\title{
Apoptosis and keratin intermediate filaments
}

\author{
RG Oshima ${ }^{*, 1}$ \\ ${ }^{1}$ Cancer Research Center, The Burnham Institute, La Jolla, CA 92037, USA \\ * Corresponding author: RG Oshima, Cancer Research Center, The Burnham \\ Institute, 10901 North Torrey Pines Road, La Jolla California, CA 92037, USA; \\ Tel: 858646 3147; Fax: 858713 6268; E-mail: rgoshima@burnham.org
}

Received 6.9.01; revised 7.11.01; accepted 14.11.01

Edited by M Piacentini

\begin{abstract}
Intermediate filament (IF) proteins utilize central $\alpha$-helical domains to generate polymeric fibers intermediate in size between actin microfilaments and microtubules. The regions flanking the central structural domains have diverged greatly to permit IF proteins to adopt specialized functions. Keratins represent the largest two groups of IF proteins. Most keratins serve structural functions in hair or epidermis. Intracellular epidermal keratins also provide strength to epithelial sheets. The intracellular type I keratins and other IF proteins are cleaved by caspases during apoptosis to ensure the disposal of the relatively insoluble cellular components. However, recent studies have also revealed an unexpected protective role for keratin 8 during TNF and Fas mediated apoptosis. Evidence for possible functions of keratins both upstream and downstream of apoptotic signaling are considered.
\end{abstract}

Cell Death and Differentiation (2002) 9, 486-492. DOI: 10.1038/ sj/cdd/4400988

Keywords: apoptosis; keratin; TNF; caspase; intermediate filament

Abbreviations: IF, intermediate filament; GFAP, glial fibrillar acidic protein; NF, neurofilament; $\mathrm{K}$, keratin; TNF, tumor necrosis factor; TNFr1, TNF receptor 1 ; TNFr2, TNF receptor 2; LT $\beta R$, lymphotoxinbeta receptor; ConA, concanavalin A; TPA, tissue polypeptide antigen; GFP, green fluorescent protein

\section{Introduction}

Three filamentous systems make up the cytoskeleton of cells. These are microfilaments, microtubules and the intermediate filaments. Sixty-five homologous proteins with the ability to form $10 \mathrm{~nm}$ filaments define the intermediate filament family in humans. ${ }^{1,2}$ They likely arose by mutation of an ancestral nuclear lamin gene ${ }^{3}$ and are restricted in expression to metazoans. ${ }^{4}$ Individual IFs have diverged and specialized their $\mathrm{N}$-terminal and C-terminal domains that flank the $\alpha$ helical central region necessary for filamentous polymerization. The proteins are divided into at least five groups as shown in Table 1. The type I and type II keratins are the largest subgroups of the intermediate filament family. The keratins polymerize as obligate heteropolymers of individual type I and type II proteins. The keratins are further subdivided into epithelial and hair related keratins. Type III IF proteins are represented by vimentin, glial fibrillary acidic protein, desmin and peripherin. Type IV IF proteins include the three forms of neurofilament proteins, $\alpha$-internexin, syncollin, nestin and synemin and the type V IF proteins represent the three nuclear lamins.

\section{Keratins}

Investigations of the functions of specific intermediate filament proteins and the identification of mutant IF proteins involved in human genetic diseases have demonstrated that many IF proteins function to provide mechanical strength to cells and tissues. This is clearly demonstrated in mammalian skin where mutations or the absence of specific epidermal keratins causes epidermal fragility resulting in blistering skin diseases $^{5-7}$ and alterations in the mechanical properties of filaments. ${ }^{8}$ Similarly, muscle mechanical defects are evident in the absence of desmin. ${ }^{9}$ In addition, A2 and A3 IF proteins of Caenorhabditis elegans are necessary for locomotion. ${ }^{4}$ The keratins associated with hair are uniquely specialized for stability reinforced by extensive extracellular disulfide bridging. The specialized keratins of the outer epidermis (K1, K2, $\mathrm{K} 9, \mathrm{~K} 10$ ) are distinguished by tail domains greatly enriched in glycine and by the lack of caspase cleavage sites within the type I extracellular keratins (K9, K10). These keratins contribute to the structural integrity essential for the barrier function of the skin. Intracellular epithelial keratins such as K5 and $\mathrm{K} 14$ crossbridge desmosomal junctions and thus provide structural continuity with the edges of epithelial cells. Individual keratins bind to the desmoplakin component of desmosomes with varying affinity and structural requirements. ${ }^{10,11}$ Additional adapter proteins also contribute to the association of IF with desmosomes. ${ }^{12}$ Keratins and Ecadherin are two defining characteristics of epithelial cells. Many simple epithelial cells are particularly sensitive to apoptosis when detached from extracellular matrix and neighboring cells in a process termed anoikis. ${ }^{13,14} \mathrm{~A}$ possible role of keratins in anoikis remains to be investigated. Multiple excellent reviews concerning the structure, dynamics and function of intermediate filaments are available., $, 5,15-20$ Further discussion here will focus on the possible roles of keratins in apoptosis.

\section{$\mathrm{K} 8$ and $\mathrm{K} 18$}

$\mathrm{K} 8$ and $\mathrm{K} 18$ are expressed in simple, or predominately single layered, internal epithelia. Several characteristics of K8 and K18 distinguish them from other members of the type I and II keratins. First, they are the first IF proteins to be expressed during mammalian development being associated with the 
differentiation to the trophectodermal layer of the blastocyst. However, the human epiblast, unlike the mouse inner cell mass, is an epithelium and expresses $\mathrm{K} 8$ and $\mathrm{K} 18$. In addition to the unique genes coding for human $\mathrm{K} 8$ and $\mathrm{K} 18$, each is represented by 35 and 62 processed pseudogenes respectively. These are distributed over many chromosomes. ${ }^{1,21}$ The large number of processed pseudogenes for K8 and K18 may reflect their expression in the human epiblast which provides a germ line target for retroviral reverse transcription. ${ }^{16}$ The smaller number of K8 and K18 pseudogenes found in mice ${ }^{21,22}$ is consistent with the difference in expression of these genes during early development. K18 is also the only type I keratin found within the type II keratin multigene locus found on human chromosome 12 . The other type I keratins are found on chromosome 17 . The genes for K8 and K18 are adjacent to each other and at the distal end of the Krt1 locus.

Another distinguishing characteristic of $\mathrm{K} 8$ and $\mathrm{K} 18$ is their common and persistent expression in carcinomas. Other keratins that are expressed in the tissue of origin of carcinomas tend to be more sporadically expressed or lost during the progression of the tumor. K8, K18 and K19 have proved to be useful carcinoma markers.

While keratins are promiscuous in their ability to heterpolymerize from different type I and II proteins in vitro, ${ }^{23,24}$ preferential assembly of certain keratin pairs in vivo has been revealed by gene knockout experiments. Thus the removal of $\mathrm{K} 18$ results in the loss of $\mathrm{K} 7$ as well as $\mathrm{K} 8$ protein in intestine. ${ }^{25}$ In the absence of a complementary partner $\mathrm{K} 8$ and $\mathrm{K} 18$ are normally degraded rapidly, although $\mathrm{K} 8$ is degraded less quickly than K18 in some cells. ${ }^{26}$ In K18 null animals, aggregates of precipitated $\mathrm{K} 8$ residue, known as Mallory bodies, are found in the livers of old animals. Thus the degradation of K8 may not necessarily be complete, at least under some pathological conditions. ${ }^{25}$

Gene targeting experiments have demonstrated that $\mathrm{K} 8$ is important for development because $\mathrm{K} 8$ deficient embryos die at $\mathrm{E} 12.5 .^{27}$ However, the viability of $\mathrm{K} 8$ deficient mice is dependent on the genetic background. ${ }^{28}$ In an FVB/N genetic background approximately $50 \%$ of the expected number of $\mathrm{K} 8$ deficient embryos are born. By contrast, the knockout of $\mathrm{K} 18$ or $\mathrm{K} 19$ does not alter viability. ${ }^{25,29}$ However, K18, K19 compound homozygote null embryos die at about 9 days of development. ${ }^{30}$ Thus K18 deficiency is compensated by $\mathrm{K} 19$ and vice versa (Table 2). K8 deficiency is also compensated to some degree by $\mathrm{K} 19$ because K8, K19 compound homozygote null embryos die earlier than K8 null embryos. ${ }^{29}$ The protective effect of K19 is likely due to low levels of $\mathrm{K} 7$, expressed in late trophoblast derivatives. This interpretation of K8, K18 and $\mathrm{K} 19$ knockouts is summarized in Table 2. However, the absence of all keratins (and very likely all IF) in K18, K19 compound homozygotes still permits keratin deficient blastocysts to implant, invade the uterine environment and develop for 9 days. If $\mathrm{K} 8$ and $\mathrm{K} 18$ primarily provide mechanical strength, it is perhaps surprising that development can proceed during trophectoderm expansion, implantation, and invasion. Furthermore, no abnormalities of parietal or visceral yolk sac development were detected during the differentiation of $\mathrm{K} 8$ deficient $\mathrm{ES}$ cells in vitro. ${ }^{31}$ Thus $\mathrm{K} 8$ is not necessary for the appearance or function of polarized epithelial yolk sac cells or the initial trophoblast derivatives. Other cytoskeletal elements may provide sufficient strength to implanting embryos until day 9 of development. However, the postimplantation failure of trophoblast derivatives may reflect additional functions for simple epithelial keratins.

\section{$\mathrm{K} 8$ and $\mathrm{K} 18$ associated disease}

The incomplete penetrance of embryonic lethality of K8 null mice has permitted the evaluation of the importance of K8 in adult mice. Adult K8 null mice in the semipermissive FVB/N background develop a mild hepatitis and a more dramatic inflammatory bowel disease by about 6 months of age. ${ }^{28}$ This condition is similar to that seen in mice without the $T$ cell

Table 1 Coding Intermediate Filament Genes

\begin{tabular}{llll}
\hline Type I & Type II & Type III & \\
\hline K9 & K1 & & $\begin{array}{l}\text { vimentin } \\
\text { desmin }\end{array}$ \\
K10 & K1b & & GFAP \\
K10b & K2e & & peripherin \\
K10c & K2p & & NF-L \\
K10d & K3 & Type IV & NF-M \\
K12 & K4 & & NF-H \\
K12b & K5 & -internexin \\
K13 & K5b & & syncollin \\
K14 & K5c & & nestin \\
K15 & K6a & & synemin \\
K16a & K6b & & \\
K17 & K6hf & & laminA/C \\
K18 & K6h & laminB1 \\
K19 & K6i & Type V \\
K20 & K6k & & \\
K23 & K6I & & laminB2 \\
& K7 & Oilensin \\
& K8 & Others & \\
Hair type I & Hair type II & & \\
KRTHA1 & Hb1 & & \\
KRTHA2 & Hb2 & & \\
KRTHA3a & Hb3 & & \\
KRTHA3b & Hb4 & & \\
KRTHA4 & Hb5 & & \\
KRTHA5 & Hb6 & & \\
KRTHA6 & & & \\
KRTHA7 & & & \\
KRTHA8 & & & \\
\hline
\end{tabular}

Data are from a survey of the human genome draft sequences. ${ }^{1}$ Intermediate filaments associated with genetic mutations in human genetic disease are indicated in bold ${ }^{1,5}$

Table 2 Keratin complementation in placenta

\begin{tabular}{|c|c|c|c|c|c|}
\hline \multirow[b]{2}{*}{ Keratin pair } & \multicolumn{5}{|c|}{ Mouse genotype } \\
\hline & K18 ko & K19 ko & K8 ko & K8/19 ko & K18/19 ko \\
\hline $\mathrm{K} 8 / \mathrm{K} 18$ & no & yes & no & no & no \\
\hline K8/K19 & yes & no & no & no & no \\
\hline $\mathrm{K} 7 / \mathrm{K} 19$ & yes & no & yes & no & no \\
\hline $\mathrm{K} 7 / \mathrm{K} 18$ & no & yes & yes & yes & no \\
\hline Viability & adult & adult & E12 & E10 & E9 \\
\hline Penetrance & - & - & $3-50 \%$ & $100 \%$ & $100 \%$ \\
\hline
\end{tabular}

Potential keratin heteropolymers are shown in the first column. Expected presence or absence of the heteropolymers are indicated as a function of the keratin genotype indicated in the first row. The onset of embryonic lethality is correlated with the absence of heteropolymers of K7, K8, K18 and K19 
receptor $\alpha^{32}$ or the IL-2 $2^{33}$ and IL- $10^{34}$ cytokines. In addition, K8 null adults were found to be particularly sensitive to pentobarbital anesthesia, partial hepatectomy ${ }^{35}$ and to liver toxicity induced by griseofulvin, 3,5-diethoxycarbonyl-1, 4dihydrocollidine ${ }^{36}$ acetaminophen ${ }^{37}$ or the phosphatase inhibitor microcystin-LR. ${ }^{38}$ In the case of griseofulvin treatment, which models the formation of Mallory bodies in alcoholic liver disease, the use of $\mathrm{K} 8$ null animals revealed that Mallory body formation was dependent on K8. However, $\mathrm{K} 8$ null animals developed liver disease even in the absence of Mallory bodies. ${ }^{36}$ Thus these dense aggregates of crosslinked and modified K8/K18 are not the causative agent of subsequent liver damage. An important role for K8/K18 in resistance to liver toxicity is reinforced by the increased sensitivity of transgenic mice which overexpress mutant forms of K18 to griseofulvin, acetaminophen and microcystinLR. $^{37,39,40}$ Recently, mutations of $\mathrm{K} 8$ in humans have been found to be associated with cryptogenic liver disease ${ }^{41}$ and inflammatory bowel disease (Birgit Lane, personal communication). In the case of crytogenic liver disease, two mutations of $\mathrm{K} 8$ have been identified. One changes a tyrosine at position 53 to a histidine $(\mathrm{Y} 53 \mathrm{H})$. The second changes a conserved glycine at position 61 to a cysteine (G61C). One consequence of the $\mathrm{G} 61 \mathrm{C}$ is disulfide bridging of $\mathrm{K} 8$, apparently to itself. Both mutations appear to alter the stability of K8/K18 filaments when cells are stressed but not under normal growth conditions. Together, the mouse and human diseases associated with $\mathrm{K} 8$ mutations indicate an important role in resistance to liver toxicity and inflammatory bowel disease. The mechanism of the protective effects of $\mathrm{K} 8 / \mathrm{K} 18$ remains to be determined.

\section{K8 and TNF sensitivity}

$A$ recent observation has implicated $K 8$ and $K 18$ in resistance to apoptosis induced by TNF family receptors. Several epithelial cell lines deficient in K8/K18 IF are more sensitive to apoptosis induced by the combination of TNF and cycloheximide than their control counterparts. ${ }^{42}$ This resistance to TNF was correlated with the ability of $\mathrm{K} 8$ but not K18 to bind to the cytoplasmic domain of TNFr2 and the lymphotoxin- $\beta$ receptor (LT $\beta \mathrm{R}$ ) but not TNFr1 or Fas. Colocalization of TNFr2 and $\mathrm{K} 8 / \mathrm{K} 18$ was detected at the periphery of cells. In addition, treatment of either $\mathrm{K} 8$ or $\mathrm{K} 18$ null animals with concanavalin $A$ (ConA) showed that the hepatocytes of both types of keratin deficient animals were more sensitive to lymphocyte initiated apoptosis. K8 and K18 are the only IF proteins expressed in hepatocytes. Thus gene targeting of either gene results in the absence of hepatocyte IF. ConA induced hepatitis acts through circulating blood elements and involves both Fas and TNF. 43,44,45 Increased levels of both TNF and Fas ligand are found in the livers of mice treated with ConA. The similar response of both $\mathrm{K} 8$ and $\mathrm{K} 18$ null animals to ConA was of particular interest because $\mathrm{K} 18$ null animals are phenotypically normal and do not develop the spontaneous mild hepatitis found in $\mathrm{K} 8$ null animals. The colonic hyperplasia of the K8 null animals may also reflect the involvement of the immune system. It is interesting that trophoblast derivatives are normally resistant to TNF induced apoptosis. ${ }^{46,47}$ It is possible that TNF sensitivity may be involved in the trophoblastic defects found in null K8 and K8, K19 and K18, K19 compound null animals.

\section{$\mathrm{K} 8$ and Fas}

Very recently, a similar role for $\mathrm{K} 8$ in protection from Fas mediated apoptosis of hepatocytes has been discovered. ${ }^{48}$ Explanted hepatocytes from K8 deficient mice are particularly sensitive to activating Fas antibody but not TNF or TRAIL. Furthermore, the increased sensitivity to Fas activating antibody was correlated with an increase in the fraction of cellular Fas on the cell surface. Total Fas levels in K8 null and wild-type hepatocytes appear similar. The increased sensitivity of K8 null animals to activating Fas antibody was found only at a moderate dose of antibody. Microtubule dissociating drugs helped protect hepatocytes from subsequent Fas antibody challenge. K8/K18 may be involved in the trafficking of Fas from the Golgi to the apical surface of polarized epithelia.

Increased Fas on the cell surface of K8 null hepatocytes may predispose them to apoptosis because over expression of death receptors can trigger the apoptotic cascade even in the absence of ligand. However, TNF is key for liver growth and regeneration as well as an apoptotic stimulus. ${ }^{49}$ Perhaps K8 hepatocytes are presensitized to Fas stimulation by previous exposure to TNF. It will be interesting to determine if $\mathrm{K} 18$ null mice also express elevated levels of hepatocyte surface Fas and to analyze the effects of TNF and Fas deficiencies on K8 null embryonic lethality.

The association of $\mathrm{K} 8 / \mathrm{K} 18$ with death receptor family function may be related to earlier implications of $K 8 / K 18$ with drug resistance in several cell lines. ${ }^{50,51}$ Some K8/K18 deficient cell lines are more sensitive to DNA damaging agents such as mitoxantrone, doxorubicin, melphalan, bleomycin, and mitomycin $\mathrm{C}$ than the controls that were engineered to express keratin. These drugs have been shown to induce surface Fas expression through a p53 dependent process in multiple cancer cells. ${ }^{52}$ Increased Fas expression sensitizes cells to FasL stimulated killing. Chemotherapeutic drug treatment sensitizes multiple cancer cell lines to either Fas or Trail killing. ${ }^{53}$ While several observations indicate that killing of cancer cells by DNA damaging agents is not exclusively dependent on Fas, ${ }^{54}$ Fas or other death receptors may contribute to the cellular damage. The role of keratin IFs in resistance to some drug induced apoptosis, may be linked to death receptors.

$\mathrm{K} 8$ and K18 have now been convincingly connected to resistance to multiple kinds of stress. ${ }^{15,19}$ This evidence includes the association of HSP70 with $\mathrm{K} 18 ;{ }^{55}$ the increased sensitivity of $\mathrm{K} 8$ null mice and $\mathrm{K} 18$ dominant negative transgenic mice to the toxicity of acetaminophen, $^{37}$ microcystin-LR ${ }^{38}$ and griseofulvin ${ }^{36}$ and the increased sensitivity of $\mathrm{K} 8$ null mice to pentobarbital and liver perfusion. ${ }^{35}$ While the correlation of various forms of stress with $\mathrm{K} 8 / \mathrm{K} 18$ filament phosphorylation is well established, the mechanism by which these keratins confer resistance or protection is less obvious. One potential common thread to many types of stress is TNF family involvement. 
However, one potential contradiction to the function of K8/K18 in moderating TNF family ligand induced pathology is the surprising lack of protective effect of either K8 or K18 on experimentally induced pancreatitis. ${ }^{56}$ TNF is reported to contribute to the severity of the experimental disease. ${ }^{57}$ However, TNF may play a secondary role in the pancreatitis models and a more direct role in several liver toxicity models.

\section{How might K8/K18 moderate TNF and Fas induced apoptosis?}

Both TNF and FasL normally induce apoptotic signaling by the engagement of the cognate receptors. However, increased surface expression of receptor can also initiate signaling. The increased sensitivity of K8 null hepatocytes to activating Fas antibody has been suggested to be a reflection of the increased proportion of Fas expressed at the cell surface. This would imply that K8/K18 filaments might specifically moderate the transport of Fas to the cell surface. This suggestion is of particular interest in light of the recent identification of abnormalities in the distribution of apical surface markers in both the small intestine and liver of K8 null animals. ${ }^{58}$ In the small intestine of K8 null animals, regional specific differences in the expression of syntaxin-3, intestinal alkaline phosphatase and CFTR chloride channel proteins were found. Given the rapid turnover of intestinal cells, these regional differences on the villi may reflect alterations in the turnover of the proteins. Syntaxin-3 is a key element of the SNARE machinery involved in specific vesicular transport. Interestingly, sytaxin-3 is co-localized with vimentin filaments in fibroblasts and Hela cells ${ }^{59}$ but is not found associated with the K18 filaments of Hela cells. The mechanism by which keratin filaments might influence vesicular trafficking of specific surface molecules remains to be elucidated. However, the recently appreciated dynamic properties of IF including rapid intracellular movement ${ }^{60}$ facilitates consideration of many possibilities.

Interference with the transport of TNFr1 from the Golgi to the cell surface has been shown to be a mechanism of inhibition of TNF induced apoptosis in poliovirus infected cells. ${ }^{61}$ This function would place K8/K18 upstream of TNFr or Fas receptor signaling. Alternatively, K8 may play a role downstream of TNFr signaling by moderating the signaling from receptors. Indirect evidence of IF involvement in signaling includes the increased NF- $\kappa \mathrm{B}$ and Jnk activation found in keratin deficient endodermal cells in response to TNF, ${ }^{42}$ the binding of $14-3-3$ protein to $\mathrm{K} 18$ in a phosphorylation dependent manner, ${ }^{62}$ and MAP kinase phosphorylation of IF proteins. ${ }^{63} \mathrm{~K} 8$ is capable of binding the cytoplasmic domain of TNFr2. However, signaling through TNFr2 is significantly different from TNFr1, as TNFr2 has no death effector domain. One example of an indirect mechanism of influencing TNF signaling is the induction of TNF on the cell surface by TNFr2 signaling which then contributes to apoptosis. ${ }^{64}$

Very recently Inagaki and colleagues ${ }^{65}$ described an alternative and likely key mechanism by which keratin attenuates TNF induced death. Residues $77-128$ of K18 and $\mathrm{K} 14$ both mediate an association with the C-terminal portion of TNFR1-associated death domain protein (TRADD). This association with a key adapter molecule was demonstrated biochemically by co-assembly, coimmunoprecipitation analysis, and by immunofluorescent localization of both endogenous and exogenous TRADD and K18. Importantly, this investigation provides evidence for the competition of ligand activated TNFR1 and keratin for TRADD that dissociates from keratin and associates with ligand bound TNFR1 to form a signaling complex that activates caspase 8 . This report provides the best present explanation of the protective effect of $\mathrm{K} 8 / \mathrm{K} 18$. The very interesting control of the association of TRADD with keratins will likely be an important focus of future investigation.

\section{Intermediate filament proteins are cleaved by caspases during apoptosis}

Nearly 30 years ago, Bjorklund developed an antibody test for tissue polypeptide antigen (TPA) that was found in the serum of cancer patients. The nature of this circulating antigen remained obscure in spite of significant use of the tumor marker, until 1984, when the antigen(s) was identified as a complex of keratin 8,18 and 19 fragments. ${ }^{66}$ This discovery helped explain the correlation of TPA with carcinoma status because most carcinoma continued to express epithelial keratin intermediate filament proteins $\mathrm{K} 8$, $\mathrm{K} 18$ and $\mathrm{K} 19 .^{67}$ However, the origin of soluble fragments of insoluble keratin was still a puzzle. In 1997, Caulin et al. demonstrated that $\mathrm{K} 18$ but not $\mathrm{K} 8$ was a substrate for caspase digestion during the course of epithelial cell apoptosis. ${ }^{68}$ Caspases 3,6 and 7 were all capable of cleaving after the aspartate $238\left(D^{238}\right)$ and mutation of the $\mathrm{DEVD}^{238}$ sequence rendered this site resistant to cleavage both in vitro and in vivo. ${ }^{68,69}$ However, the $\mathrm{K} 18$ internal cleavage site is utilized in apoptotic MCF-7 cells which are deficient in caspase $3 .^{70}$ Thus caspase 3 is not essential for $K 18$ cleavage at $D^{238}$. A second cleavage site nearer the $C$ terminal end was deduced on the basis of a ten residue, monoclonal antibody epitope terminating with a potential caspase cleavage site, DALD, ${ }^{397}$ that rendered antibody binding dependent on apoptotic cleavage of $\mathrm{K} 18 .^{71}$ The identification of $D^{397}$ as the second caspase cleavage site of $\mathrm{K} 18$ was confirmed by mutagenesis. ${ }^{72}$

The first intermediate filament protein to be identified as a caspase substrate was the nuclear lamin $A .^{73,74}$ The internal cleavage site of lamin $A$ is identical to that found in $\mathrm{K} 18$. This cleavage site of $\mathrm{K} 18$ and other IF proteins is found within the L1-2 linker region between two conserved, central, alpha helical domains (Figure 1). ${ }^{75}$ None of the type II keratins have similar potential cleavage sites. Simple alignment of other IF proteins lead to the prediction that other type I keratins and vimentin, desmin and NF-M would likely be caspase substrates. Caspase cleavage at the L1-2 linker region has been confirmed for $K 14, K 17$, $K 19$, and vimentin. ${ }^{72,76}$ The L1-2 caspase cleavage site of multiple type I keratins is of particular interest because mutations of the caspase recognition site have been found in K14 of patients with epidermolysis bullosa simplex, a genetic blistering skin disease. However, a careful analysis 


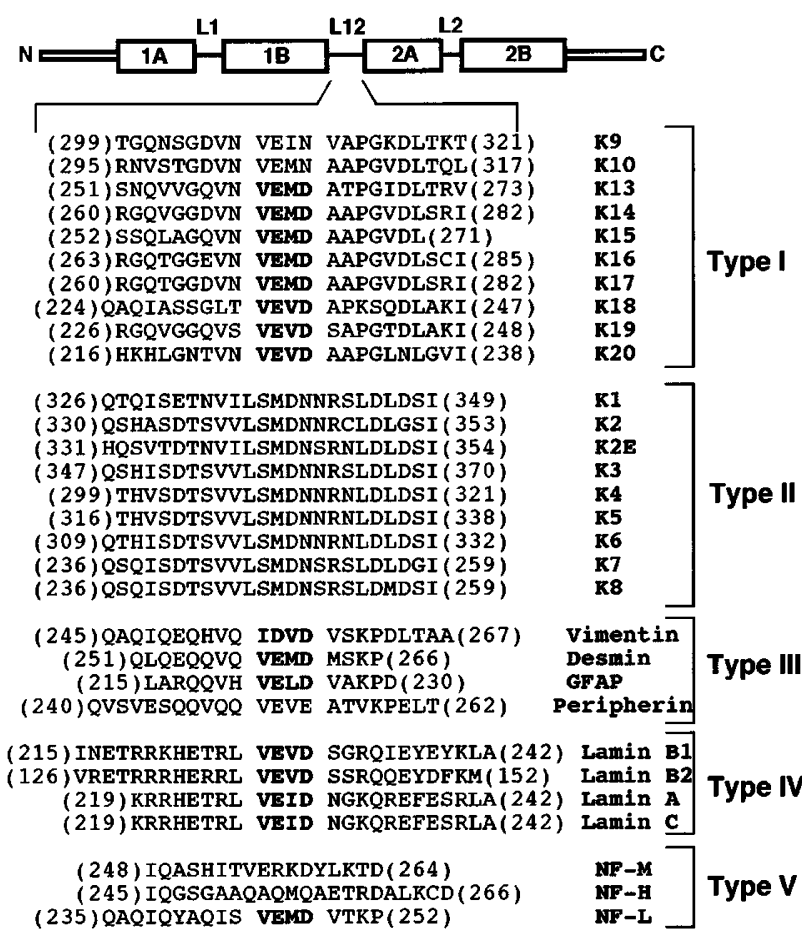

Figure 1 Conservation of caspase cleavage site of type I keratins and other IF protein. A schematic diagram of the domain structure of IF proteins is shown at the top. The L1-2 linker region connects the coil 1B and coil 2A subdomains. Note the conservation of the VEVD or VEMD caspase recognition sites except in $\mathrm{K} 9$ and $\mathrm{K} 10$ which function as extracellular barrier proteins in epidermis and the absence of similar sites in type II keratins (reprinted with permission from the Journal of Cell Biology) ${ }^{68}$

of four spontaneous mutations within the context of $\mathrm{K} 14$ revealed that only the mutation of the required aspartate (VEVD or VEMD) prevented cleavage of K14 during apoptosis. $^{72}$ Confirmation of the cleavage of the wt sequence VEMD/A of $\mathrm{K} 14$ suggests that other type I keratins, $\mathrm{K} 12-17$, desmin and neurofilament-L may also be caspase substrates.

\section{Consequences of caspase digestion of IF during apoptosis}

The orderly packaging and disposal of cellular contents during cell death may be important to limit inflammatory reaction. The cleavage of IF during apoptosis may reflect the programmed disposal of relatively insoluble structural proteins. The engagement of Fas with FasL, or activating antibody results in the formation of a signaling complex involving proteins with death effector domains such as FADD and the subsequent activation of caspase 8 . Caspase 8 translocates from either a membrane or mitochondrial location to plectin, an abundant cytoskeletal scaffolding protein which binds all three cytoskeletal fibers, actin, intermediate filaments and microtubules. The subsequent cleavage of plectin by caspase 8 results in a reorganization of the microfilament system. ${ }^{70}$ The early cleavage of plectin appears not to affect intermediate filament organization. Soon after an apoptotic challenge K8/K18 filaments are
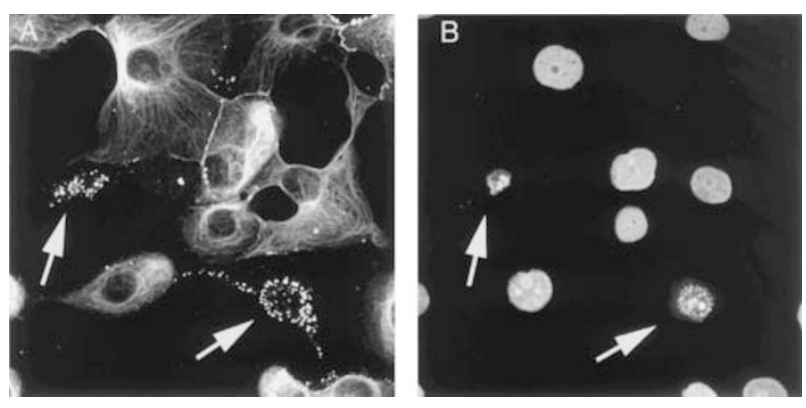

Figure 2 K18 reorganization during epithelial cell apoptosis. SNG-M human adenocarcinoma cells were treated with etoposide, then fixed and stained with K18 monoclonal antibody and propidium iodide for nuclear morphology. (A) K18. (B) DNA fluorescence. Arrows point to apoptotic cells. Note the reorganization of keratin filaments into granules and the apoptotic nuclear morphology. Similar granular structures also react preferentially with K18 phospho-serine 53 specific antibody ${ }^{68}$

hyperphosphorylated and collapse to punctate inclusions of variable size (Figure 2). Similar K18 aggregations have been observed in some epithelial cells not undergoing apoptosis ${ }^{77}$ and may reflect the consequences of keratin phosphorylation. ${ }^{63}$ During TRAIL induced apoptosis, activated caspase 3 co-localizes with similar, though larger aggregates late in the process of death. ${ }^{78}$ This organization into dense aggregates without a limiting membrane appears to contain most of the activated caspase 3 and the K18 that has been cleaved at position $D^{397}$. The status of the VEVD ${ }^{238}$ cleavage site in such aggregates is not known. If the association of active caspase 3 with these aggregates is strictly dependent on the presence of $\mathrm{K} 18$, it is possible that keratins may provide some protection against caspase 3 digestion by limiting the availability of active caspase 3 .

The hyperphosphorylation of $\mathrm{K} 18$ in cells treated with okadaic acid, a phosphatase inhibitor, was found to render K18 resistant to caspase digestion at $D^{238}$ but not $D^{397} .^{72}$ This is an interesting result in light of the rapid phosphorylation of $\mathrm{K} 18$ on serine 53 after apoptosis initiation. ${ }^{68,69,79}$ The reorganization of $\mathrm{K} 18$ filaments in apoptotic cells is associated with the cleavage of $\mathrm{K} 18$ at $\mathrm{D}^{397}$, K18 phosphorylation at $\mathrm{S}^{53}$, and the association of active caspase 3 with the $\mathrm{K} 18$ granules. However, it is not clear whether the reorganization of keratin filaments is caused by its phosphorylation alone, its cleavage or even an association with other proteins within the cells. Dissection of the roles of $\mathrm{K} 18$ phosphorylation, its association with caspase 3 and caspase cleavage of K18 may reveal new ways to regulate caspase activity.

While the initial observations linking intermediate filaments and apoptosis involved lamins and keratins, other IF proteins may also function during the process. For example, vimentin is a caspase substrate. ${ }^{76,80}$ Furthermore, the forced expression of the $\mathrm{N}$-terminal caspase digestion product of vimentin as a GFP fusion protein has been reported to induce caspase dependent apoptosis. ${ }^{76}$ This effect is suggested to amplify the death signal. However, the effect has only been reported with the GFP fusion protein and the natural $\mathrm{N}$-terminal caspase product of vimentin has not been detected in apoptotic cells suggest- 
ing that it may be further degraded rapidly. Additional investigation should reveal whether the subtle phenotypes of the vimentin knockout ${ }^{81,82}$ may be supplemented by a functional role in apoptosis.

In summary, simple epithelial keratins have been implicated in resistance to drug toxicity, hepatic stress and inflammatory bowel disease. Recent connections of death receptor involvement with epithelial apoptosis in both cell lines and mouse models should stimulate further advances in understanding the possible functions of programmed cell death.

\section{Acknowledgements}

I am grateful to Normal Marceau for communicating recent results before publication and to Bishr Omary, Pierre Coulombe and Helene Baribault for helpful discussion. This work was supported by a grant from the National Cancer Institute (CA 42302).

\section{References}

1. Hesse M, Magin TM and Weber K (2001) Genes for intermediate filament proteins and the draft sequence of the human genome: Novel keratin genes and a surprisingly high number of pseudogenes related to keratin genes 8 and 18. J. Cell Sci. 114: 2569-2575

2. Fuchs E and Weber K (1994) Intermediate Filaments: structure, dynamics, function, and disease. Ann. Rev. Biochem. 63: 345-382

3. Weber K, Plessmann U and Ulrich W (1989) Cytoplasmic intermediate filament proteins of invertebrates are closer to nuclear lamins than are vertebrate intermediate filament proteins; sequence characterization of two muscle proteins of a nematode. EMBO J. 8: 3221-3227

4. Karabinos A, Schmidt H, Harborth J, Schnabel R and Weber K (2001) Essential roles for four cytoplasmic intermediate filament proteins in Caenorhabditis elegans development. Proc. Natl. Acad. Sci. USA 98: 7863-7868

5. Fuchs $E$ and Cleveland DW (1998) A structural scaffolding of intermediate filaments in health and disease. Science 279: 514-519

6. Fuchs E, Chan YM, Paller AS and Yu QC (1994) Cracks in the foundation: keratin filaments and genetic disease. Trends Cell Biol. 4: 321-326

7. Fuchs E (1997) Of mice and men: genetic disorders of the cytoskeleton. Mol. Biol. Cell 8: 189-203

8. Ma LL, Yamada S, Wirtz D and Coulombe PA (2001)A "hot-spot" mutation alters the mechanical properties of keratin filament networks. Nat. Cell Biol. 3: $503-$ 506

9. Li Z, Colucci-Guyon E, Pincon-Raymond M, Merickskay M, Pournin S, Paulin D and Babinet C (1996) Cardiovascular lesions and skeletal myopathy in mice lacking desmin. Dev. Biol. 175: 362-366

10. Meng J-J, Bornslaeger EA, Green KJ, Steinert PM and Ip W (1997) Two-hybrid analysis reveals fundamental differences in direct interactions between desmoplakin and cell type-specific intermediate filaments. J. Biol. Chem. 272: 21495-21503

11. Smith $E A$ and Fuchs $E$ (1998) Defining the interactions between intermediate filaments and desmosomes. J. Cell Biol. 141: 1229-1241

12. Ouyang $P$ and Sugrue SP (1996) Characterization of pinin, a novel protein associated with the desmosome-intermediate filament complex. J. Cell Biol. 135 1027-1042

13. Frisch SM and Francis $H$ (1994) Disruption of epithelial cell-matrix interactions induces apoptosis. J. Cell Biol. 124: 619-626

14. Frisch SM and Screaton RA (2001) Anoikis mechanisms. Curr. Opin. Cell Biol. 13: $555-562$

15. Coulombe PA and Omary MB (2002) 'Hard' and 'soft' principles defining the structure, function and regulation of keratin intermediate filaments. Curr. Opin. Cell Biol. in press.

16. Oshima RG, Baribault $\mathrm{H}$ and Caulin $\mathrm{C}$ (1996) Oncogenic regulation and function of keratin 8 and 18. Cancer Metastasis Rev. 15: 445-471

17. Chou YH and Goldman RD (2000) Intermediate filaments on the move. J. Cell Biol. 150: F101-F106.
18. Coulombe PA, Bousquet O, Ma L, Yamada S and Wirtz D (2000) The 'ins' and 'outs' of intermediate filament organization. Trends Cell Biol. 10: 420-428

19. Ku N-O, Zhou X, Toivola DM and Omary MB (1999) The cytoskeleton of digestive epithelia in health and disease. Amer. J. Physiol. 277: 1108-1137

20. Herrmann $\mathrm{H}$ and Aebi $U$ (2000) Intermediate filaments and their associates: multi-talented structural elements specifying cytoarchitecture and cytodynamics. Curr. Opin. Cell Biol. 12: 79-90

21. Oshima RG, Trevor K, Shevinsky LH, Ryder OA and Cecena G (1988) Identification of the gene coding for the endothelial $B$ murine cytokeratin and its methylated, stable inactive state in mouse nonepithelial cells. Genes Dev. 2: $505-516$

22. Vasseur M, Duprey P, Brulet $P$ and Jacob F (1985) One gene and one pseudogene for the cytokeratin endothelial A. Proc. Natl. Acad. Sci. USA 82: 1155-1159

23. Hatzfeld M and Franke WW (1985) Pair formation and promiscuity of cytokeratins: formation in vitro of heterotypic complexes and intermediate-sized filaments by homologous and heterologous recombinations of purified polypeptides. J. Cell Biol. 101: 1826-1841

24. Karabinos A, Riemer D, Erber A and Weber K (1998) Homologues of vertebrate type I, II and III intermediate filament (IF) proteins in an invertebrate: the IF multigene family of the cephalochordate Branchiostoma.FEBS Lett. 437: 15-18

25. Magin TM, Schroder R, Leitgeb S, Wanninger F, Zatloukal K, Grund C and Melton DW (1998) Lessons from keratin 18 knockout mice: formation of novel keratin filaments, secondary loss of keratin 7 and accumulation of liver-specific keratin 8positive aggregates. J. Cell Biol. 140: 1441-1451

26. Kulesh DA, Cecena G, Darmon YM, Vasseur M and Oshima RG (1989) Posttranslational regulation of keratins: degradation of unpolymerized mouse and human keratins 18 and 8. Mol. Cell Biol. 9: 1553-1565

27. Baribault H, Price J, Miyai K and Oshima RG (1993) Mid-gestational lethality in mice lacking keratin 8. Genes Dev. 7: 1191-1202

28. Baribault H, Penner J, lozzo RV and Wilson-Heiner M (1994) Colorectal hyperplasia and inflammation in keratin 8-deficient FVB/N mice. Genes Dev. 8: 2964-2973

29. Tamai Y, Ishikawa T-O, BosI MR, Mori M, Nozaki M, Baribault H, Oshima RG and Taketo MM (2000) Cytokeratins 8 and 19 in the mouse placental development. J. Cell Biol. 151: 563-572

30. Hesse M, Franz T, Tamai Y, Taketo MM and Magin TM (2000) Targeted deletion of keratins 18 and 19 leads to trophoblast fragility and early embryonic lethality. EMBO J. 19: 5060-5070

31. Baribault $H$ and Oshima RG (1991) Polarized and functional epithelia can form after the targeted inactivation of both mouse keratin 8 alleles. J. Cell Biol. 115 $1675-1684$

32. Mombaerts P, Mizoguchi E, Grusby MJ, Glimcher LH, Bhan AK and Tonegawa ST (1993) Spontaneous development of inflammatory bowel disease in T cell receptor mutant mice. Cell 75: 275-282

33. SadlackB, Merz H, SchorleH, SchimplA, FellerAC and HorakI(1993) Ulcerative colitis-like disease in mice with a disrupted interleukin-2 gene. Cell 75: 253-261

34. Kuhn R, Lohler J, Rennick D, Rajewsky K and Muller W (1993) Interleukin-10deficient mice develop chronic enterocolitis. Cell 75: 263-274

35. Loranger A, Duclos S, Grenier A, Price J, Wilson-Heiner M, Baribault H and Marceau N (1997) Simple epithelium keratins are required for maintenance of hepatocyte integrity. Amer. J. Pathol. 151: 1673-1683

36. Zatloukal K, Stumptner C, Lehner M, Denk H, Baribault H, Eshkind LG and Franke WW (2000) Cytokeratin 8 protects from hepatotoxicity, and its ratio to cytokeratin 18 determines the ability of hepatocytes to form Mallory bodies. Am. J. Pathol. 156: 1263-1274

37. Ku N-O, Michie S, Soetikno R, Resurreccion E, Oshima RG and Omary MB (1996) Susceptibility to hepatotoxicity in transgenic mice that express a dominant-negative human keratin 18 mutant. J. Clin. Invest. 98: 1034-1046

38. Toivola DM, Omary MB, Ku N-O, Peltola O, Baribault H and Eriksson JE (1998) Protein phosphatase inhibition in normal and keratin 8/18 assemblyincompetent mouse strains supports a functional role of keratin intermediate filaments in preserving hepatocyte integrity. Hepatology 28: 116-128

39. Ku N-O, Michie S, Oshima RG and Omary MB (1995) Chronic hepatitis, hepatocyte fragility, and increased soluble phosphoglycokeratins in transgenic mice expressing a keratin 18 conserved arginine mutant. J Cell Biol 131: 13031314

40. Omary MB and Ku NO (1997) Intermediate filament proteins of the liver: emerging disease association and functions. Hepatology 25: 1043-1048 
41. Ku NO, Gish R, Wright TL and Omary MB (2001) Keratin 8 mutations in patients with cryptogenic liver disease. New Eng. J. Med. 344: 1580-1587

42. Caulin C, Ware CF, Magin TM and Oshima RG (2000) Keratin-dependent, epithelial resistance to tumornecrosis factor-induced apoptosis. J. Cell Biol. 149: $17-22$

43. Tagawa Y-I, Kakuta S and Iwakura Y (1998) Involvement of Fas/Fas ligand system-mediated apoptosis in the development of concanavalin A-induced hepatitis. Euro. J. Immunol. 28: 4105-4113

44. Ksontini R, Colagiovanni DB, Josephs MD, Edwards III CK, Tannahil CL, Solorzano CC, Norman J, Denham W, Clare-Salzler M, MacKay SLD and Moldawer LL (1998) Disparate roles for TNF- $\alpha$ and Fas ligand in Concanavalin Ainduced hepatitis. J. Immunol. 160: 4082-4089

45. Zhang H, Cook J, Nickel J, Yu R, Stecker K, Myers K and Dean NM (2000) Reduction of liver Fas expression by an antisense oligonucleotide protects mice from fulminant hepatitis. Nat. Biotechnol. 18: 862-867

46. Rasmussen CA, Pace JL, Banerjee S, Phillips TA and Hunt JS (1999) Trophoblastic cell lines generated from tumour necrosis factor receptor-deficient mice reveal specific functions for the two tumour necrosis factor receptors Placenta 20: 213-222

47. Drake BL and Head JR (1990) Murine trophoblast cells are not killed by tumo necrosis factor- $\alpha$. J. Reprod. Immunol. 17: 93-99

48. GilbertS, Loranger A, Daigle N and Marceau N(2001) Simple epithelium keratins 8 and 18 provide resistance to fas-mediated apoptosis. The protection occurs through a receptor-targeting modulation. J. Cell Biol. 154: 763-774

49. Yamada Y, Kirillova I, Peschon JJ and Fausto N (1997) Initiation of liver growth by tumor necrosis factor: deficient liver regeneration in mice lacking type I tumor necrosis factor receptor. Proc. Natl. Acad. Sci. USA 94: 1441-1446

50. Bauman PA, Dalton WS, Anderson JM and Cress AE (1994) Expression of cytokeratin confers multiple drug resistance. Proc. Natl. Acad. Sci. USA 91 5311-5314

51. Anderson JM, HeindI LM, Bauman PA, Ludi CW, Dalton WS and Cress AE (1996) Cytokeratin expression results in a drug-resistant phenotype to six different chemotherapeutic agents. Clin. Cancer Res. 2: 97-105

52. MullerM, WilderS, BannaschD, Israeli D, LehlbachK, Li-Weber M, Friedman SL, Galle PR, Stremmel W, Oren M and Krammer PH (1998) p53 activates the CD95 (APO-1/Fas) gene in response to DNA damage by anticancer drugs. J. Exp. Med 188: $2033-2045$

53. Lacour S, Hammann A, Wotawa A, Corcos L, Solary E and Dimanche-Boitrel MT (2001) Anticancer agents sensitize tumor cells to tumor necrosis factor- related apoptosis-inducing ligand-mediated caspase-8 activation and apoptosis. Cancer Res. 61: 1645-1651

54. Kaufmann SH and Earnshaw WC (2000) Induction of apoptosis by cancer chemotherapy. Exp. Cell Res. 256: 42-49

55. Liao J, Lowthert LA, Ghori N and Omary MB (1995) The 70-kDa heat shock proteins associated with glandular intermediate filaments in an ATP-dependent manner. J. Biol. Chem. 270: 915-922

56. Toivola DM, Baribault H, Magin T, Michie SA and Omary MB (2000) Simple epithelial keratins are dispensable for cytoprotection in two pancreatitis models. Am. J. Physiol. Gastrointest. Liver Physiol. 279: G1343-1354

57. Denham W, Yang J, Fink G, Denham D, Carter G, Ward K and Norman J (1997) Gene targeting demonstrates additive detrimental effects of interleukin 1 and tumor necrosis factor during pancreatitis. Gastroenterology 113: 1741-1746

58. Ameen NA, Figueroa $Y$ and Salas PJ (2001) Anomalous apical plasma membrane phenotype in CK8-deficient mice indicates a novel role for intermediate filaments in the polarization of simple epithelia. J. Cell Sci. 114 $563-575$

59. Faigle W, Colucci-Guyon E, Louvard D, Amigorena S and Galli T (2000) Vimentin filaments in fibroblasts are a reservoir for SNAP23, a component of the membrane fusion machinery. Mol. Biol. Cell 11: 3485-3494

60. Goldman RD, Chou Y-H, Prahlad V and Yoon M (1999) Intermediate filaments: dynamic processes regulating their assembly, motility, and interactions with other cytoskeletal systems. FASEB J. 13: 261-265

61. Neznanov N, Kondratova A, Chumakov KM, Angres B, Zhumabayeva B, Agol V and Gudkov A (2001) Poliovirus protein 3A inhibits TNF-induced apoptosis by eliminating TNF receptor from the cell surface. J. Virol. 75: 10409-10420

62. Liao J and Omary MB (1996) 14-3-3 proteins associate with phosphorylated simple epithelial keratins during cell cycle progression and act as a solubility cofactor. J. Cell Biol. 133: 345-357
63. Ku N-O, Liao J, Chou C-F and Omary MB (1996) Implications of intermediate filament protein phosphorylation. Cancer Metastasis Rev. 15: 429-444

64. Grell M, Zimmermann G, Gottfried E, Chen CM, Grunwald U, Huang DC, Wu Lee YH, Durkop H, Engelmann H, Scheurich P, Wajant H and Strasser A (1999) Induction of cell death by tumour necrosis factor (TNF) receptor 2, CD40 and CD30: a role for TNF-R1 activation by endogenous membrane-anchored TNF. EMBO J. 18: $3034-3043$

65. Inada H, Izawa I, Nishizawa M, Fujita E, Kiyono T, Takahashi T, Momoi T and Inagaki M (2001) Keratin attenuates tumor necrosis factor-induced cytotoxicity through association with TRADD. J. Cell Biol. 155: 415-425

66. Weber K, Osborn M, Moll R, Wiklund B and Luning B (1984) Tissue polypeptide antigen (TPA) is related to the non-epidermal keratins 8,18 and 18 typical of simple and non-squamous epithelia: re-evaluation of a human tumor marker. EMBO J. 3: 2707-2714

67. Moll R, Franke WW, Schiller DL, Geiger B and Krepler R (1982) The catalog of human cytokeratins: patterns of expression in normal epithelia, tumors and cultured cells. Cell 31: 11-24

68. Caulin C, Salvesen GS and Oshima RG (1997) Caspase cleavage of keratin 18 and reorganization of intermediate filaments during epithelial apoptosis. J. Cell Biol. 138: 1379-1394

69. Ku N-O, Liao J and Omary MB (1997) Apoptosis generates stable fragments of human type I keratins. J. Biol. Chem. 272: 33197-33203

70. Stegh AH, Herrmann H, Lampel S, Weisenberger D, Andra K, Seper M, Wiche G, Krammer PH and Peter ME (2000) Identification of the cytolinker Plectin as a major early in vivo substrate for caspase 8 during CD95- and tumor necrosis factor receptor-mediated apoptosis. Mol. Cell Biol. 20: 5665-5679

71. Leers MP, Kolgen W, Bjorklund V, Bergman T, Tribbick G, Persson B, Bjorklund P, Ramaekers FC, Bjorklund B, Nap M, Jornvall H and Schutte B (1999) Immunocytochemical detection and mapping of a cytokeratin 18 neo-epitope exposed during early apoptosis. J. Pathol. 187: 567-572

72. Ku NO and Omary MB (2001) Effect of mutation and phosphorylation of type 1 keratins on their caspase-mediated degradation. J. Biol. Chem. 276: 2679226798

73. Takahashi A, Alnemri ES, Lazebnik YA, Fernandes-Alnemri T, Litwack G and Moir RD (1996) Cleavage of lamin A by Mch2 alpha but not CPP32: multiple interleukin 1 beta-converting enzyme-related proteases with distinct substrate recognition properties are active in apoptosis. Proc. Natl. Acad. Sci. USA 93: 8395-8400

74. Lazebnik YA, Takahashi A, Moir RD, Goldman RD, Poirier GG, Kaufmann SH and Earnshaw WC (1995) Studies of the lamin proteinase reveal multiple parallel biochemical pathways during apoptosis execution. Proc. Natl. Acad. Sci. USA 92: $9042-9046$

75. Prasad S, Soldatenkov VA, Srinivasarao G and Dritschilo A (1999) Intermediate filament proteins during carcinogenesis and apoptosis. International J. Oncol. 14: $564-570$

76. Byun Y, Chen F, Chang R, Trived M, Green KJ and Cryns VL (2001) Caspase cleavage of vimentin disrupts intermediate filaments and promotes apoptosis. Cell Death Differ. 8: 443-450

77. Franke WW, Schmid E and Grund C (1982) Intermediate filament proteins in nonfilamentous structures: transient disintegration and inclusion of subunit proteins in granular aggregates. Cell 30: 103-113

78. MacFarlane M, Merrison W, Dinsdale D and Cohen GM (2000) Active caspases and cleaved cytokeratins are sequestered into cytoplasmic inclusions in TRAILinduced apoptosis. J. Cell Biol. 148: 1239-1254

79. Ku N-O and Omary MB (1994) Identification of the major physiologic phosphorylation site of human keratin 19: potential kinases and a role in filament reorganization. J. Cell Biol. 127: 161-171

80. Muller K, Dulku S, Hardwick SJ, Skepper JN and Mitchinson MJ (2001) Changes in vimentin in human macrophages during apoptosis induced by oxidised low density lipoprotein. Atherosclerosis 156: 133-144

81. Eckes B, Colucci-Guyon E, Smola H, Nodder S, Babinet C, Krieg T and Martin P (2000) Impaired wound healing in embryonic and adult mice lacking vimentin. J. Cell Sci. 113: 2455-2462

82. Colucci-Guyon E, Portier M-M, Dunia I, Paulin D, Pournin S and Babinet C (1994) Mice lacking veimentin develop and reproduce without an obvious phenotype. Cell 79: 679-694 